\title{
Presence of Acetylated and Shortened Endorphins in Human Fetal Pituitary Gland
}

\author{
FABIO FACCHINETTI, ANNA RITA STORCHI, FELICE PETRAGLIA, AND \\ ANDREA R. GENAZZANI \\ Department of Obstetrics and Gynecology, University of Modena, School of Medicine, Modena, Italy
}

\begin{abstract}
A total of 21 human fetal pituitaries was collected from spontaneous abortions (11 cases) or prostaglandin (PG)-induced abortions at the second trimester. Pituitaries were homogenized, fractionated by HPLC, and the fractions were tested by specific RIA for $\alpha$-endorphin (EP) ( $\beta$-EP 1-16), $\gamma$-EP ( $\beta$-EP 1-17), $\beta$-EP ( $\beta$-EP 1-31), and their $\alpha-\mathrm{N}$-acetylated derivatives. In the fetal pituitaries collected after spontaneous abortion, the contents of $\alpha$-EP $(23.4 \pm 7.5 \mathrm{pmol} / \mathrm{mg}$ prot, mean $\pm \mathrm{SE})$ and $\gamma$-EP $(28.9 \pm$ 9.7) were similar to those of $\beta$-EP $(28.6 \pm 7.4)$. Both $\beta$ $\mathrm{EP} / \alpha$-EP $(1.2 \pm 0.3)$ and $\beta$-EP/ $\gamma$-EP $(1.1 \pm 0.3)$ ratios approached unity. Although 35.7 and $30.2 \%$ of $\alpha$-EP and $\gamma$-EP were acetylated, acetyl- $\beta$-EP was only $8.4 \%$ of the total $\beta$-EP immnoreactivity. In the five cases of PG-induced abortion that were more than 20 wk of pregnancy, the pituitary content of $\beta$-EP (75.9 \pm 21.2$)$ and $\gamma$-EP (26.2 \pm 7.5) were significantly higher than in samples collected after spontaneous abortion $(13.3 \pm 8.2$ and $5.9 \pm 1.8$, respectively, $p<0.01)$. On the contrary, neither $\alpha$-EP $(31.3 \pm 5.2)$, acetyl- $\alpha$-EP $(0.94 \pm 0.28)$, acetyl- $\gamma$-EP $(0.65$ $\pm 0.07)$, acetyl- $\beta$-EP $(0.35 \pm 0.05)$ pituitary contents in PG-induced abortions differed from those measured after spontaneous abortion $(\alpha$-EP: $25.6 \pm 6.6$; acetyl- $\alpha$-EP: 0.92 \pm 0.41 ; acetyl- $\gamma$-EP: $0.82 \pm 0.30$; acetyl- $\beta$-EP: $0.96 \pm$ 0.44). In fetal pituitaries collected between the 13th and the 17th wk of pregnancy, no differences were seen comparing PG-induced and spontaneous abortions. These data demonstrate that in the fetal pituitary: 1 ) $\beta$-EP retains its opioid biologic activity because only a small percentage is acetylated, 2) shortened endorphins are quantitatively as important as $\beta$-EP, and 3) after mid-gestation, the fetal proopiomelanocortin synthesis or processing may be sensitive to endocrine or environmental stimuli. (Pediatr Res 25:652-655, 1989)
\end{abstract}

\section{Abbreviations}

EP, endorphin

Ac, acetyl

PG, prostaglandin

The human fetus at term responds to the stress of delivery by secreting the typical stress hormones derived from proopiomelanocortin, i.e. ACTH and $\beta$-EP (1-3). Physiologic labor and fetal distress seem to be the main stimulants of $\beta$-EP release at birth, and the analgesic properties of the endogenous opioid are supposed to be fundamental in overcoming the moments of

Received June 29, 1988; accepted September 28, 1988.

Correspondence Dr Fabio Facchinetti, Clinica Ostetrica e Ginecologica, Università degli Studi, Via del Pozzo 71, 41100 Modena, Italy. parturition (4-6). Moreover, a significant secretion of $\beta$-EP occurs in the neonatal period, both in vaginally delivered babies and in those born by cesarean section in the absence of labor, suggesting that neonatal $\beta$-EP secretion is an important factor of extrauterine adaptation $(7,8)$. Fetal pituitary contains ACTH (9) and $\beta$-EP from the early stages of development (10-12), and secretion has been documented in vitro after the 20th wh of pregnancy (13). However, the biologic activity of $\beta$-EP may change during fetal life because $\beta$-EP represents the precursor for smaller peptides, such as $\alpha$ - and $\gamma$-endorphins with psychostimulant and neuroleptic-like profiles, respectively $(14,15)$. Moreover, $\beta$-EP may be acetylated at its $\mathrm{N}$-terminus, losing its opioid properties (16). In some mammals, the $\alpha$-N-acetyltransferase activity is lacking in anterior pituitary and is typical of the neurointermediate lobe $(17,18)$. This is present in the human fetus but involutes after birth and is normally absent as an anatomically differentiated structure in the adult human pituitary (19).

This study evaluated the possible presence and the gestationrelated changes of $\alpha-\gamma$ - and $\beta$-EP, and of their respective acetylated forms, in fetal pituitaries.

\section{MATERIALS AND METHODS}

Tissues. Fetal pituitaries were collected immediately after abortion in 11 cases (five cases between the 13th and the 17th wk and six between the 20th and the 25th wk of pregnancy). Spontaneous abortions were due to oligohydramnios (five cases) or to cervical incompetence (4). In two other cases, hysterotomy for multiple myomas was performed at the 13th and 14th wk of pregnancy. Then 10 additional pituitaries were collected after PG-induced abortion during the second trimester (five cases between the 14th and 17th wk and the others between the 20th and 23th wk of pregnancy). The abortion was performed for suspected rubella infection (four cases) or for psychologic maternal reasons. Only one fetus, however, showed malformations possibly caused by rubella. Repeated injections of the PG derivative 16-phenoxy- $\omega$-tetranor-PGE $\mathrm{PG}_{2}$ methylsulphonylamide (Nalador, Schering, FRG; $500 \mu \mathrm{g}$ intramuscularly every $4 \mathrm{~h}$ ) induced uterine contractions similar to those of labor (20). Abortion occurred 8-16 h later.

Peptide separation. After boiling in $0.5 \mathrm{M}$ acetic acid for 10 min, pituitaries were homogenized and the supernatants were submitted to an HPLC fractionation, whereas pellets underwent total protein measurement using phenol reagents.

The HPLC apparatus (Waters Instruments, Inc., Rochester, $\mathrm{MN}$ ) was equipped with a reverse phase, C-18 $\mu$ Bondapak column, $3.9 \times 300 \mathrm{~mm}, 10-\mu \mathrm{m}$ particle size. The elution was carried out in a convex gradient, starting from 18 to $33 \%$ acetonitrile in $0.01 \mathrm{~N}$ hydrochloric acid in $15 \mathrm{~min}$, followed by a further increase of acetonitrile to $36 \%$ in $10 \mathrm{~min}$ (Fig. 1, first panel, dotted line). Flow rate was adjusted to $1.5 \mathrm{ml} / \mathrm{min}$. After discarding the 1st min of elution, 54 fractions were collected (each 30 
s), dried, redissolved in $1 \mathrm{ml}$ of $0.12 \mathrm{M}$ phosphate buffer, $\mathrm{pH}$ 7.4 , containing $0.1 \% \mathrm{BSA}$ and analyzed for peptide immunoreactivities by different RIA. The retention times of the various reference peptides are indicated by arrows in Figure 1.

To avoid contamination, the column was washed with $100 \%$ acetonitrile at the end of the gradient, and a "blank run" was done after each sample. To evaluate the amount of material possibly sticking on the column, $10 \mathrm{ng}$ each of the peptides was injected and processed as described above. More than $90 \%$ of $\alpha$ EP, $\gamma$-EP, $\gamma$-EP, and acetyl- $\beta$-EP were recovered. Then 1 to $3.5 \%$ were measured in the blank run, and no detectable amounts of any peptide were measurable by RIA in the next run. This means that the peptide content of one pituitary does not contaminate that of the next pituitary applied to the chromatography. To avoid shadowing of standards in the RIA, the calibration of the column (using $1-2 \mu \mathrm{g}$ of reference peptides) was done at the end of sample runs and column washed with diluted nitric acid and methanol. To assess the function of the column in between sample runs, we used $0.2 \mu \mathrm{g}$ of Met-Enkephalin, which does not cross-react with the antisera used.

Peptide RIA. Antisera against $\alpha$-EP (A2) and $\gamma$-EP (L2) were supplied by Dr. V. Wiegant (Utrecht, The Netherlands) (22). Anti- $\alpha$-EP serum reacts $100 \%$ with $\alpha$-EP and less than $1 \%$ with both $\gamma$-EP and $\beta$-EP. Anti- $\gamma$-EP serum reacts $100 \%$ with $\gamma$-EP, $4 \%$ with $\beta$-EP, and $8 \%$ with $\alpha$-EP. Antiserum against C-terminal $\beta$-EP was a generous gift of Prof. C. H. Li (San Francisco, CA). It recognizes $16 \%$ of $\beta$-LPH and fully reacts with acetylated forms (23). Antiserum against $\alpha$-N-Ac- $\beta$-EP was a gift from Dr. J. Funder (Melbourne, Australia). This serum reacts equally with
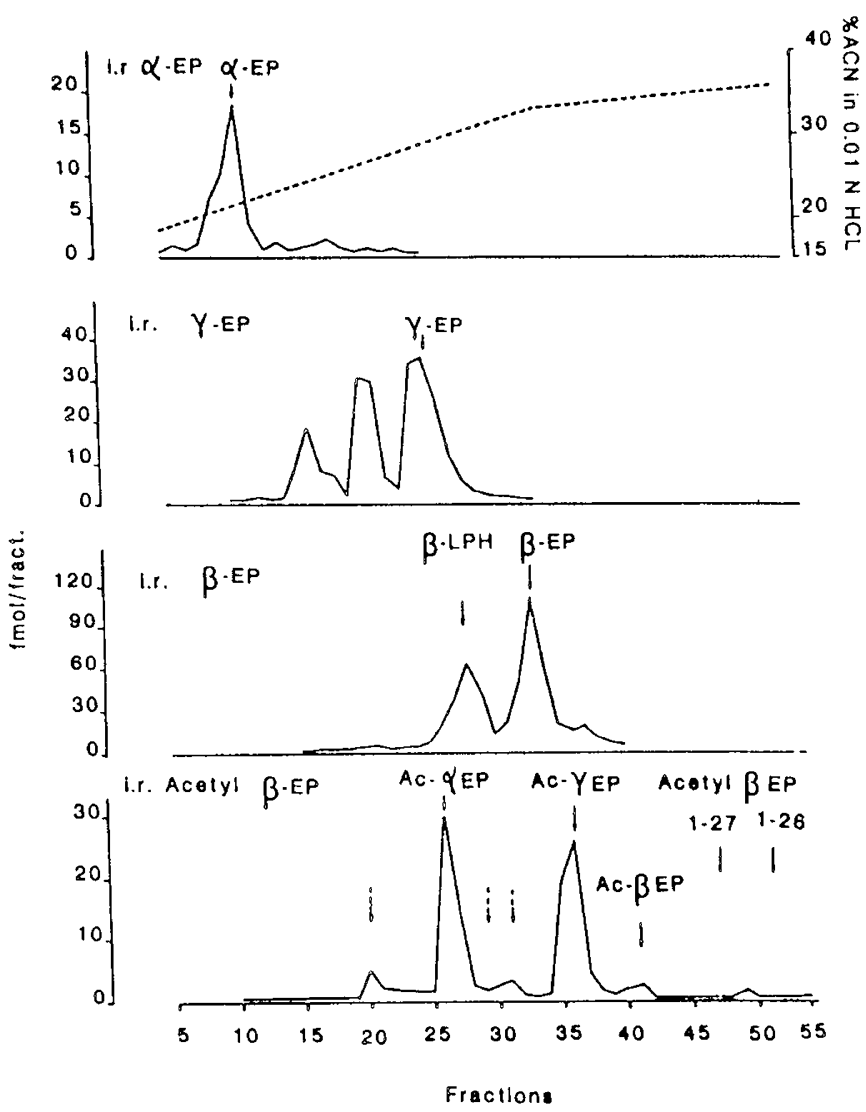

Fig. 1. $\alpha$-EP, $\gamma$-EP, $\beta$-EP, and acetyl- $\beta$-EP immunoreactivities in a pool of three fetal pituitaries at 20-25th wk of pregnancy, obtained after spontaneous abortion. Arrows indicate the retention times of reference peptides. The second peak in panel 2 could probably be referred to a "big" form of $\gamma$-EP (1-77 $\gamma$-EP) (28). In the last panel, arrows with dotted line indicate the retention times of the oxidized forms of Ac- $\alpha$ $\mathrm{EP}, \mathrm{Ac}-\gamma-\mathrm{EP}$ and Ac- $\beta$-EP, respectively.
Ac- $\alpha$-EP, Ac- $\gamma$-EP, Ac- $\beta$-EP 1-27, and Ac- $\beta$-EP 1-26, and does not recognize non-acetylated forms (24).

The RIA were performed in $0.3 \mathrm{ml}$ vol; incubations lasted 24 $\mathrm{h}$ (with a preincubation of $18 \mathrm{~h}$ in the case of $\beta$-EP) and were stopped by adding polyethylene glycol $18 \%$ carried over with horse serum. For each sample, the concentration of a given peptide is calculated by adding the peak value to those of the two adjacent fractions. If the immunoreactive peak eluted 1 min away of the expected time, the values were not taken into consideration.

\section{RESULTS}

Figure 1 reports profiles of immunoreactivity using the different antisera raised against $\alpha$-EP, $\gamma$-EP, $\beta$-EP and Ac-endorphins. Significant immunoreactive peaks coeluted in the region where reference peptides eluted, thus demonstrating that $\alpha$-EP, $\gamma$-EP, and their acetylated derivatives were present in the fetal pituitary (Fig. 1). Lower but detectable amounts of Ac- $\beta$-EP and Ac- $\beta$-EP 1-27. were also demonstrated, whereas no immunoreactivity was found in the region where Ac $\beta$-EP $1-26$ elutes. The dotted arrows in the bottom panel of Figure 1 refer to the elution time of oxidized forms of Ac- $\alpha-\mathrm{EP}, \mathrm{Ac}-\gamma-\mathrm{EP}$, and Ac- $\beta$-EP, respectively. Such immunoreactivity possibly due to oxidized forms of ac-endorphins represented less than $5 \%$ of the immunoreactivity of the parent peptide.

In fetal pituitaries collected after spontaneous abortion during the whole second trimester, the contents of $\alpha$-EP $(23.4 \pm 7.5$ $\mathrm{pmol} / \mathrm{mg}$ prot, mean $\pm \mathrm{SE})$ and $\gamma$-EP $(28.9 \pm 9.7)$ were similar to those of $\beta$-EP $(28.6 \pm 7.4$ ) (Fig. 2$)$ and both $\beta$-EP/ $\alpha$-EP (1.2 $\pm 0.3)$ and $\beta$-EP $/ \gamma$-EP $(1.1 \pm 0.3)$ ratios approached unity. A significant correlation between $\beta$-EP and $\alpha$-EP $(r=0.76, p<$ $0.01)$, and $\beta$-EP and $\gamma$-EP $(r=0.61, p<0.05)$ was found. Only $8.4 \%$ of immunoreactive $\beta$-EP was acetylated, whereas both Ac$\alpha$-EP and Ac- $\gamma$-EP represented 35.7 and $30.2 \%$, respectively, of the total immunoreactivity (Fig. 2). In PG-induced abortions performed after the 20th wk of pregnancy, the pituitary content of $\beta$-EP $(75.9 \pm 21.2)$ and $\gamma$-EP $(26.2 \pm 7.5)$, but not of $\alpha$-EP $(31.3 \pm 5.2)$, were significantly higher than in samples collected after spontaneous abortion at the same gestational age $(\beta$-EP: $13.3 \pm 8.2, p<0.01 ; \gamma$-EP: $5.9 \pm 1.8, p<0.01 ; \alpha$-EP: $25.6 \pm$ 6.6) (Fig. 3). On the contrary, neither Ac- $\alpha$-EP $(0.94 \pm 0.28)$, Ac- $\gamma$-EP $(0.65 \pm 0.07)$, nor Ac- $\beta$-EP $(0.35 \pm 0.09)$ pituitary contents in PG-induced abortions differed from those measured in spontaneous abortion $(0.92 \pm 0.41,0.82 \pm 0.30$, and $0.96 \pm$ 0.44 , respectively) (Fig. 3). However, in fetal pituitaries collected between the 13 th and the 17 th wk of pregnancy no differences were seen between PG-induced $(\beta$-EP: $19.4 \pm 3.7 ; \alpha$-EP: $16.1 \pm$ $4.1 ; \gamma$-EP: $35.6 \pm 14.8$; Ac- $\beta$-EP: $2.45 \pm 0.51$; Ac- $\alpha$-EP: $11.2 \pm$ 6.5; Ac- $\gamma$-EP: $15.4 \pm 4.2$ ) and spontaneous abortion ( $\beta$-EP: 39.2

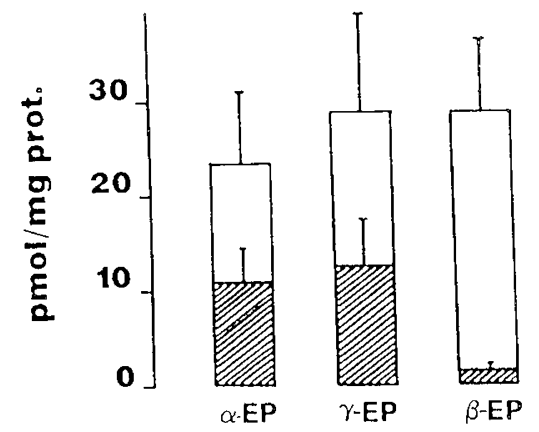

Fig. 2. Pituitary contents (mean $\pm \mathrm{SE}$ ) of $\alpha$-EP, $\gamma$-EP, and $\beta$-EP (open bars), and their respective acetylated forms (shaded bars) in samples obtained from spontaneous abortion between the 13 th and the 25 th wk of pregnancy. No significant differences were found between the three endorphins, whereas the contents of Ac- $\alpha$-EP and Ac- $\gamma$-EP are significantly higher than those of Ac- $\beta$-EP. 


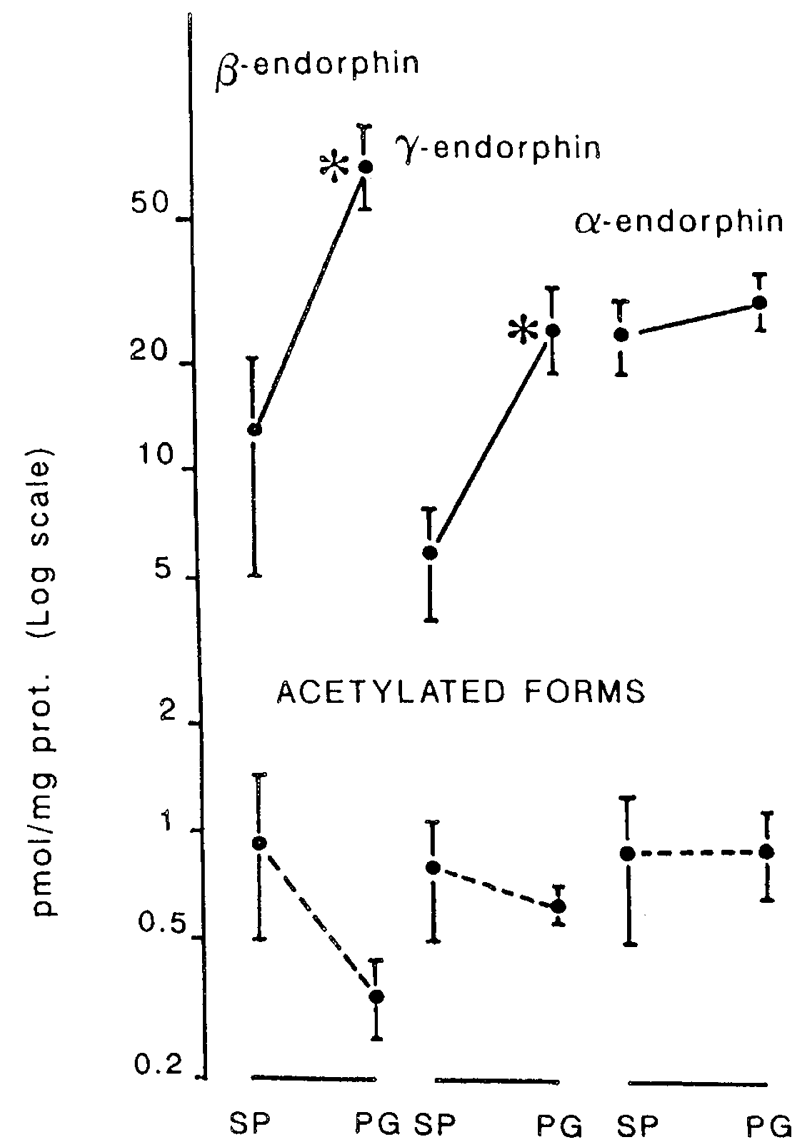

Fig. 3. Pituitary content (mean \pm SE, logarithmic scale) of the different endorphins and their acetylated forms in fetuses delivered after prostaglandin-induced labor $(P G)$ at 20-25th wk of pregnancy compared to those undergoing spontaneous abortion $(S P)$ at the same gestational age. Asterisks indicate a significant difference between PG and SP group $(p<0.01)$.

$\pm 16.0 ; \alpha$-EP: $20.1 \pm 4.8 ; \gamma$-EP: $42.8 \pm 19.1 ;$ Ac- $\beta$-EP: $1.4 \pm$ 0.74; Ac- $\alpha$-EP: $14.2 \pm 8.6$; Ac- $\gamma$-EP: $13.9 \pm 3.2$ ).

\section{DISCUSSION}

These data show that immunoreactive $\alpha$-EP and $\gamma$-EP, and their acetylated derivatives, are present in the human fetal pituitary gland. The presence of $\beta$-EP was confirmed $(10-12,25)$. In the fetuses studied at the different gestational ages, $\alpha$-EP and $\gamma-$ EP were present in near equimolar amounts to $\beta$-EP. This is consistent with the in vitro evidence suggesting that $\beta$-EP $1-31$ could represent the immediate precursor of $\alpha$-EP and $\gamma$-EP (26). Also in two adult pituitary glands the contents of $\alpha$-EP and $\gamma-$ $\mathrm{EP}$ were equivalent to those of $\beta$-EP (27), and larger peptides containing $\alpha$-EP and $\gamma$-EP sequences at their C-terminus have been proposed as possible precursor molecules (28).

Despite equimolar amounts of the three endorphins in fetal pituitary, Ac- $\beta$-EP was one-fourth of Ac- $\alpha$-EP and Ac- $\gamma$-EP. This is qualitatively and quantitatively different from that found in adult whole pituitary glands, where Ac- $\beta$-EP is less than $1 \%$ of total immunoreactive $\beta$-EP, and lower contents of both Ac- $\alpha$-EP and Ac- $\gamma$-EP are found (29). Thus, our observations contribute to understanding the metabolism of proopiomelanocortin in fetal pituitary $(9,10,30)$. Considering that in mammals $\alpha$-N-acetyltransferase activity is confined to the intermediate lobe $(17,18)$, we may assume that the significant amount of Ac- $\alpha-E P$ and Ac$\gamma$-EP found in our study would mainly originate from this compartment. This agrees with studies in the adult rat, in which the intermediate lobe is well differentiated and allows an easy dissection from pars distalis $(31,32)$. However, important differ- ences in the acetylation pattern of $\beta$-EP and $\alpha$-MSH seem to exist between human and rat pituitary $(30,33)$.

The lower rate of acetylation of $\beta$-EP in comparison to its related shortened peptides in the fetal pituitary could be due either to the existence of different acetylating enzymes (34) or to the effect of dopamine, which selectively increases the acetylation rate of $\beta$-EP fragments (35). Moreover, a selective Ac- $\beta$-EP release (instead of Ac- $\alpha$-EP and Ac- $\gamma$-EP) might determine the decrease of pituitary content.

Different kinds of endocrine or environmental stimuli induce the anterior $(36,37)$ and intermediate $(38,39)$ lobe to synthesize and secrete proopiomelanocortin-products. The present data showed that pituitary $\beta$-EP and $\gamma$-EP contents in fetuses obtained after PG-induced abortion were higher than in those collected after spontaneous abortion. Such a difference was only present in fetuses older than $20 \mathrm{wk}$ of gestation, confirming that the mechanisms regulating proopiomelanocortin secretion or metabolism are active only after mid-gestation (13). Moreover, whether the differences between spontaneous and PG-induced abortion are dependent on a direct $P G$ stimulation of the pituitary remains to be established (40).

In the fetal pituitaries obtained from PG-induced abortions, the content of acetylated endorphins remained unchanged, whereas opiate-active endorphin contents increased. This could be due either to a preferential synthesis of non-acetylated forms or to an increased release. This second possibility seems unlikely in view of the findings obtained in the fetal lamb. In this animal, although Ac- $\beta$-EP represents most of the total immunoreactive $\beta$-EP circulating in the plasma, only opiate active $\beta$-EP was released into the blood stream during experimental hypoxia (41). Furthermore, we recently showed that the injection of $P G$ for inducing abortion at the second trimester increased both maternal plasma and amniotic fluid $\beta$-EP and $\beta$-lipotropin levels (42).

In summary, these data demonstrate that in the fetal pituitary $\beta$-EP is acetylated only to a small extent, mostly retaining its opioid activity. Short-chain endorphins are also contained in the gland either in native and acetylated form. The fetal synthesis or processing of proopiomelanocortin is sensitive to endocrine or environmental stimuli, but only after midgestation.

Acknowledgments. The authors are indebted to Dr. Wiegant (Rudolf Magnus Institute of Pharmacology, University of Utrecht) for his supply of $\alpha$-EP and $\gamma$-EP antisera and standards. Similarly, we are grateful to Prof. C. H. Li (University of California at San Francisco) for his supply of anti $\beta$-EP serum and to Dr. J. Funder (Medical Research Centre, Prince Henry's Hospital, Melbourne) for his gift of anti Ac-EP serum.

\section{REFERENCES}

1. Csontos K, Rust M, Hollt V, Mahr W, Kromer W, Teschemacher HJ 1979 Elevated plasma $\beta$-endorphin levels in pregnant women and their neonates. Life Sci 25:835-844

2. Genazzani AR, Facchinetti F, Parrini D $1981 \beta$-lipotropin and $\beta$-endorphin plasma levels during pregnancy. Clin Endocrinol 14:409-416

3. Goland RS, Wardlaw SL, Stark RI, Frantz AG 1981 Human plasma $\beta$ endorphin during pregnancy, labor and delivery. J Clin Endocrinol Metab 52:74-78

4. Wardlaw SL, Stark RL, Baxi L, Frantz AG 1979 Plasma $\beta$-endorphin and $\beta$ lipotropin in the human fetus at delivery: correlation with arterial $\mathrm{pH}$ and $\mathrm{pO}_{2}$. J Clin Endocrinol Metab 49:888-891

5. Shaaban MM, Hung TT, Hofmann DI, Goebelsman U $1982 \beta$-endorphin and $\beta$-lipotropin concentrations in umbilical cord blood. Am J Obstet Gynecol 144:560-568

6. Facchinetti F, Bagnoli F, Petraglia F, Parrini D, Sardelli S, Genazzani AR 1983 Feto-maternal opioid levels and parturition. Obstet Gynecol 62:764-768

7. Facchinetti F, Bagnoli F, Bracci R, Genazzani AR 1982 Plasma opioids in the first hours of life. Pediatr Res 16:95-98

8 . Pohjavuori M, Rovamo L, Laatikainen T 1985 Plasma immunoreactive $\beta$ endorphin and cortisol in the newborn infant after elective caesarian section and after spontaneous labour. Eur J Obstet Gynecol Reprod Biol 19:67-74

9 .Silman RE, Chard T, Lowry PJ, Smith I, Young IM 1976 Human foetal pituitary peptides and parturition. Nature 260:716-718

10. Vuolteenaho O, Leppaluoto J, Hoybtya M, Hirvonen J $1983 \beta$-endorphin-like peptides in autopsy pituitaries from adults, neonates and foetuses. Acta 
Endocrinol 102:27-34

11. Begeot F, Dubois MP, Dubois PM 1982 Comparative study in vivo and in vitro of the differentiation of immunoreactive corticotropic cells in fetal rat anterior pituitary. Neuroendocrinology 35:255-262

12. Facchinetti F, Storchi AR, Petraglia F, Garuti G, Genazzani AR 1987 Ontogeny of pituitary $\beta$-endorphin and related peptides in the human embryo and fetus. Am J Obstet Gynecol 156:735-739

13. Gibbs DM, Stewart RD, Liu JH, Vale W, Rivier J, Yen SSC 1982 Effects of synthetic corticotropin-releasing factor and dopamine on the release of immunoreactive $\beta$-endorphin/ $\beta$-lipotropin and melanocyte-stimulating hormone from human fetal pituitaries in vitro. J Clin Endocrinol Metab 55:1149-1152

14. Graf L, Ronai AZ. Bajusz S, Cseh G, Szekely JI 1976 Opioid agonist activity of $\beta$-lipotropin fragments: a possible biological source of morphine-like substances in the pituitary. FEBS Lett 64:181-186

15. Van Ree JM, De Wied D 1982 Neuroleptic-like profile of gamma-type endorphins as related to schizophrenia. Trends Pharmacol Sci 3:358-361

16. Smyth DG, Massey DE, Zakarian S, Finnie MDA 1979 Endorphins are stored in biologically active and inactive form: isolation of alpha- $\mathrm{N}$-acetyl peptides. Nature 279:252-254

17. "Glembotski CC 1982 Acetylation of alpha-melanotropin and $\beta$-endorphin in the rat intermediate pituitary. J Biol Chem 257:10493-10500

18. Leenders HJ, Janssens JJW, Theunissen HJM, Jenks BG, Van Overbeeke AP 1986 Acetylation of melanocyte-stimulating hormone and $\beta$-endorphin in the pars intermedia of the perinatal pituitary gland in the mouse. Neuroendocrinology 43:166-174

19. Asa SL, Kovacs K, Laszlo FA, Domokos I, Ezrin C 1986 Human fetal adenohypophysis. Neuroendocrinology 43:308-315

20. Schmidt-Gollwitzer K, Schussler B, Elger W, Schmidt-Gollwitzer M 1980 Improvement in artificial second trimester abortion with a new tissueselective prostaglandin $E_{2}$ derivative. Am J Obstet Gynecol 137:867-868

21. Loeber JG, Verhoef J, Burbach JPH, Witter A 1979 Combination of high pressure liquid chromatography and radioimmunoassay is a powerful tool for the specific and quantitative determination of endorphins and related peptides. Biochem Biophys Res Commun 86:1288-1295

22. Facchinetti F, Perez-Fernandes R, Toma MO, Gaudiero GJ, Lechuga MJ, Devesa J Genazzani AR 1988 Dopamine acts on acetylation of proopiomelanocortin-derived products in dog pituitary. Acta Endocrinol 117:33-38

23. Genazzani AR, Nappi G, Facchinetti F, Mazzella GL, Parrini D, Sinforiani E, Petraglia F, Savoldi F 1982 Central deficiency of $\beta$-endorphin in alcohol addicts. J Clin Endocrinol Metab 55:583-586

24. Cheng MC, Clements JA, Smith AI, Lolait SJ, Funder JW 1985 N-acetyl endorphin in rat spermatogonia and primary spermatocytes. J Clin Invest 75:832-835

25. Brubaker PL, Baird AC, Bennet HPJ, Browne CA, Solomon S 1982 Corticotropic peptides in the human fetal pituitary. Endocrinology 111:1150-1156

26. Burbach JPH, Loeber JG, Verhoef J, De Kloef ER, De Wied D 1980 Selective conversion of $\beta$-endorphin into peptides related to alpha- and gammaendorphin. Nature 283:96-97

27. Burbach JPH, Wiegant VM 1984 Isolation and characterization of alphaendorphin and gamma-endorphin from single human pituitary glands. FEBS Lett 166:267-272

28. Dorsa DM, Majumdar LA 1983 Localization and identification of gammaendorphin and $\beta$-endorphin-like peptides in the hypothalamus and ventral forebrain of the rat. Life Sci 33:337-345

29. Smith AI, Cheng MC, Funder JW 1985 The identification and characterization of alpha- $\mathrm{N}$-acetylated $\beta$-endorphin in the human pituitary gland. FEBS Lett 185:109-111

30. Facchinetti F, Storchi AR, Furani S, Radi D, Genazzani AR 1988 Pituitary changes of des-acetyl alpha-melanocyte stimulating hormone throughout development. Biol Neonate 54:86-92

31. Fukuta J, Nakai J, Imura H 1979 Presence of immunoreactive alpha-endorphin in rat pituitary gland. Life Sci 25:541-546

32. Dorsa DM, Chapman MB, Baskin DG 1982 Gamma-endorphin-like peptides in pituitary tissue: evidence for their existence in vivo. Peptides 3:455-459

33. Alessi NE, Khachaturian H, Watson S, Akil H 1983 Postnatal ontogeny of acetylated and non-acetylated $\beta$-endorphin in rat pituitary. Life Sci 33(suppl 1): $57-60$

34. Loh YP, Brownstein MJ, Gainer H 1984 Proteolysis in neuropeptide processing and other neural functions. Annu Rev Neurosci 7:189-222

35. Auteliano DJ, Smith AI, Lolait SJ, Funder JW 1985 Dopaminergic agents differentially alter $\beta$-endorphin processing patterns in the rat pituitary neurointermediate lobe. Neurosci Lett 59:141-146

36. Smith AI, Funder JW 1988 Proopiomelanocortin processing in the pituitary, central nervous sytem and peripheral tissues. Endocrinol Rev 9:159-179

37. Axelrod J, Reisine TD 1984 Stress hormones: their interaction and regulation. Science 224:452-455

38. Przewlocki R, Millan MJ, Gramsch GH, Millan MH, Herz A 1982 The influence of selective adeno- and neurointermedio-hypophysectomy upon plasma and brain levels of $\beta$-endorphin and their responses to stress in rats. Brain Res 242:107-113

39. Akil H, Shiomi H, Matthews J 1984 Induction of the intermediate pituitary by stress: synthesis and release of nonopioid form of $\beta$-endorphin. Science 227:424-426

40. Marsh JM, Le Maire WJ 1974 Cyclic AMP accumulation and steroidogenesis in the human corpus luteum: effect of gonadotropins and prostaglandins. $\mathbf{J}$ Clin Endocr Metab 38:99-104

41. Stark RI, Wardlaw SL, Daniel SS 1986 Characterization of plasma $\beta$-endorphin immunoreactivity of the fetal lamb: effects of gestational age and hypoxia. Endocrinology 119:755-761

42. Genazzani AR, Petraglia F, Di Meo G, Santoro V, Facchinetti F, Segre A 1987 Prostaglandin-induced mid-pregnancy abortion increases plasma and amniotic fluid levels of $\beta$-lipotropin and $\beta$-endorphin. Gynecol Obstet Invest 24:23-27 